\title{
Physical Education and Teaching Mode of College Female Students Research in Sichuan Agricultural University
}

\author{
Yuanyuan Feng1, a, Suqiong Feng', b, * \\ ${ }^{1}$ School of Sichuan Agricultural University, Ya'an 625014, China; \\ ${ }^{2}$ School of Sichuan Agricultural University, Chengdu 611130, China. \\ a397078129@qq.com, bFengtingting0828@163.com
}

\begin{abstract}
This paper uses the methods of literature, data statistics, surveyed the Sichuan Agricultural University student physique condition, test and statistics, comparative analysis and summarizes the Sichuan Agricultural University girls' physical status and characteristics. Results: Sichuan Agricultural University student physique and health condition overall is good, but the existence of the decline of the physical quality, analyze the causes for this problem, designed to essentially improve female students' physical education teaching mode, cultivate lifelong sports consciousness, habit and ability, to better promote the health sports curriculum reform provide a realistic basis.
\end{abstract}

Keywords: Physical education; teaching mode; college female students.

\section{Introduction}

That is the quality of the body's constitution refers exhibited in hereditary and acquired on the basis of morphological and physiological body functions and integrated state structure and characteristics of psychological factors, common physical, physical fitness, adaptability and mental state, and many other indicators to measure. Physical condition has a profound impact on the social development of a country. With the deepening of China's reform of higher education as well as the further implementation of the "National Student Physical Health Standards", which greatly promoted the improvement of university students' physique and health, as well as the study of reform of college sports, it has had a positive role in promoting. However, the yearly increase in college enrollment, college students accounted for one-third of the number of female students physical and health problems are not optimistic, most indicators of Female Students in College showed a downward trend, the core of the work of troubled college physical education problem. Accordingly, the concerned physical health of female students to study reform of college sports in the problems and take appropriate measures to grasp the correct direction is an urgent task currently sports workers.

\section{Materials and Methods}

This paper selects 2011 female college students from Sichuan Agricultural University, and randomly selects 500 human subjects. According to "national student physical health standards", in October 2011, October 2014, it was tested. Research methods: 1. The measurement method, according to the requirements of the national student physical health standard "and rules, specific contents are shown in table $1 ; 2$. The literature material law, written retrieval mainly for reading sports and non-sports class related to students' physique of books, papers, academic report, etc.; 3. The mathematical statistics method, the survey data under Windows XP EXCEL software is adopted to improve the statistical analysis.

\section{Results}

3.1 Body Shape, Function and Quality of Female College Students in the Two Times (Table 2).

Table 2 shows that there is no significant difference between the body shape index and the enrollment of the students after 2 years of Physical Education $(\mathrm{P}>0.05)$. But physical function and quality index were significantly improved compared with the school. During the University, the female body development has entered a mature stage; the shape index tends to be stable. Through 
physical exercise, students' physical function and quality indicators are stable development, and reached a higher level, which fully shows the effect of physical exercise and physical education.

Table 1 Sichuan Agricultural University student physical fitness test content

\begin{tabular}{|c|c|c|}
\hline Test content & Test index & Derived index \\
\hline Body shape & Height and weight & Body mass index (BMI) \\
\hline Body function & Vital capacity, step test & $\begin{array}{l}\text { Cardiac functional capacity } \\
\qquad \text { (FC) }\end{array}$ \\
\hline $\begin{array}{l}\text { Physical } \\
\text { quality }\end{array}$ & $\begin{array}{l}\text { Standing long jump, sit and reach (female), grip } \\
\text { (male) }\end{array}$ & \\
\hline
\end{tabular}

Table 2 Sophomore female college students body shape, function and quality $(\overline{\mathrm{x}} \pm \mathrm{s})$

\begin{tabular}{ccccccc}
\hline Height $(\mathrm{cm})$ & $\begin{array}{c}\text { weight } \\
(\mathrm{kg})\end{array}$ & $\begin{array}{c}\text { forced vital } \\
\text { capacity }(\mathrm{ml})\end{array}$ & $\begin{array}{c}\text { standing long } \\
\text { jump }(\mathrm{cm})\end{array}$ & step test & $\begin{array}{c}\text { body } \\
\text { antexion } \\
(\mathrm{CM})\end{array}$ \\
\hline $\mathrm{X} 1-\mathrm{X} 2$ & $159.15 \pm 4.12$ & $50.20 \pm 4.43$ & $2882.60 \pm 320.46$ & $173.30 \pm 13.25$ & $76.69 \pm 14.18$ & $15.78 \pm 5.53$ \\
& 0.42 & -0.28 & 16.60 & 12.10 & 13.32 & 2.14 \\
\hline
\end{tabular}

(Note: the X1, X2, X3, respectively, for the girls in Sichuan agricultural university entrance, sophomore and senior physical indicators)

\subsection{Body Shape, Function and Quality of the Female Senior Students (Table 3).}

Table 3 shows that senior female college students body shape index than at the end of the sophomore PE increased slightly, the body function, quality indices than sophomore fell sharply at the end of the physical education, the indicators have significant difference $(\mathrm{P}<0.05)$. Because this is the end of the compulsory course for sports, female college students' lack of consciousness, junior, senior grade can not insist for a long time to take part in physical exercise, moreover don't exercise, coupled with the employment pressure, learning burden, make its senior testing physical deterioration. It is the appeal reason lead to female students' physical function and quality levels were significantly decreased.

Table 3 senior female college students body shape, function and quality $\overline{(\mathrm{x}} \pm \mathrm{s})$

\begin{tabular}{ccccccc}
\hline Height $(\mathrm{cm})$ & $\begin{array}{c}\text { weight } \\
(\mathrm{kg})\end{array}$ & $\begin{array}{c}\text { forced vital } \\
\text { capacity }(\mathrm{ml})\end{array}$ & $\begin{array}{c}\text { standing long } \\
\text { jump }(\mathrm{cm})\end{array}$ & step test & $\begin{array}{c}\text { body } \\
\text { antexion } \\
(\mathrm{CM})\end{array}$ \\
\hline $\mathrm{X} 2-\mathrm{X} 3$ & $159.17 \pm 4.18$ & $52.10 \pm 4.42$ & $2881.30 \pm 318.86$ & $171.50 \pm 13.35$ & $72.35 \pm 9.374$ & $13.54 \pm 5.51$ \\
& 0.02 & 1.90 & 1.30 & -1.80 & -4.34 & -2.24 \\
\hline
\end{tabular}

Female college students is an important part of social resources, plays an irreplaceable role in the historical development, therefore, their physical conditions should cause the attention of the department of education of colleges and universities, to strengthen the college girls as a key to the implementation of the constitution, to avoid the body quality drop too fast, causing the girl's whole quality decline, resulting in some unexpected results. Through this research, understand the health status of Sichuan agricultural university girl, analyzed the present situation of the constitution, can the girl of Sichuan agricultural university sports teaching adjustment to provide some basis, and according to the girl of Sichuan agricultural university of physical education teaching mode for some reform and adjustment. 


\section{Analysis and Discussion}

In traditional physical education guiding ideology, there is no lack of health to the body. But in the teaching goal to set up, mainly cultivate sports skill for a long time, and as a sports teaching achievement evaluation content. The traditional teaching mode is always can't keep up with The Times and the needs of the country, college sports teaching reform. Rising in recent years but only focus on the "club" type of teaching meet the students interests and autonomy, lost the sports teaching should also have the function of the diversity of information and health guidance and responsibility, therefore, no matter adopt what kind of teaching mode will be biased.

Under this big background, comprehensive reform of undergraduate course teaching in Sichuan agricultural university, Sichuan agricultural university on the basis of the original teaching model and combined with their own characteristics, the reform of the physical education teaching, sports teaching mode " $3+3$ ", namely, under the credit system in the first semester freshman year, the second semester freshman and sophomore three semesters of the first semester opening sports compulsory courses, 16 hours per semester, each time 1 credits, and combined with "choose teachers and choose projects, choose a class time" three independent launch of elective courses, the teaching form of 16 hours per semester, each time 1 credits, to a certain extent, make up for the insufficiency of compulsory sports some aspects. In addition, with the market-oriented sports and economy, Sichuan agricultural university sports elective teaching more emphasis on its interest, confused and students be fond of emerging fashion project into the physical education class. Visible, the sports teaching model not only focuses on the learning of traditional sports and basic physical quality training, and pay more attention to students' interests and needs, increase the initiative and enthusiasm of the students to participate in physical exercise.

Sichuan agricultural university, this kind of teaching mode, first of all, according to the differences between girls and boys, divide into classes teaching students according to their aptitude; And then to the girl's social attributes and needs in one's life, and connecting with the girl's physical development, choose appropriate teaching content, such as aerobics, such as badminton, sports dance, tai chi, to shape the girl's body, cultivate their temperament, and, in turn, enhanced physique, improve their health; On this basis, the formation of the attention at ordinary times learning "process", weakening the final quantitative "results" close to the diversity of students' physical and mental development of physical education teaching evaluation system.

\section{Conclusion}

2011 girls in Sichuan agricultural university physical test results of statistical analysis showed that: during the period of university, girl's physical development has entered a stage of maturity, stable body shape indices, after two years of system of physical exercise, sophomore girls body function and physical quality index compared with school improvement; But as sport and at the end of the compulsory courses, and study the burden of aggravating, internships, employment, love, relationship stress factors, such as making the indicators of female college students in university fourth grade show significant downward trend.

The overall decline in average college female students' physical fitness, colleges and universities in the process of female physical deterioration has unavoidable responsibility, colleges and universities sports education teaching goal, the education pattern, education content and teaching evaluation should take into account the girl on the choice of the individual differences and social attribute. According to the characteristics of female college students, in the sports teaching, strengthen the girl lifetime sports thought education, change the girl not correct ideas of sports view and bad thought tendency, grasp the basic physical quality enhancement, the characteristics of female college students and create suitable for sports, environment and conditions, actively organize girls take part in all kinds of sports activities and sports competition. Let the female college students to strengthen the sports consciousness and health awareness, efforts to develop positive and healthy 
sports life style, improve the level of female college students' self-care ability and physical health, led to our school, and even other colleges and universities in our province sports work to a new level.

\section{References}

[1] Deng Yuening. The "triple independent" elective course of physical education curriculum as the main body pattern effect analysis [J]. Journal of sports. 2007, 10.

[2] Zhongwei Zhao. College students physical deterioration factors and PE intervention study [J]. Journal of Beijing sport university. 2008, 2.

[3] Zhang Shaosheng. Look from the physical findings [J]. Journal of colleges and universities sports teaching reform sports vol. 2001, 1.

[4] Guo Zhen. University students' physique status quo thinking [J]. Journal of sport culture Tribune. 2013, [5] Meng Huanhuan. From the perspective of improve female college students physical fitness [J]. Journal of college sports reform physical education. 2012, 6. 